Check for updates

Cite this: RSC Adv., 2019, 9, 1679

Received 1st November 2018

Accepted 25th December 2018

DOI: $10.1039 / c 8 \mathrm{ra09043b}$

rsc.li/rsc-advances

\section{Boron/nitrogen co-doped carbon synthesized from waterborne polyurethane and graphene oxide composite for supercapacitors $\uparrow$}

\begin{abstract}
Rui Li, Chuanli Qin, Xuxu Zhang, Zitong Lin, Shixian Lv and Xiankai Jiang (DD*
We report B/N co-doped carbon materials synthesized by an efficient and easy one-step carbonization method with ferric catalyst treatment from a precursor with boric acid treatment after the formation of the composite between waterborne polyurethane (WPU) and graphene oxide (GO). The nitrogen content was improved with the introduction of numerous melamine in the synthetic process of WPU. In addition, WPU possessed a repetitive basic unit urethane bond (-NHCOO); thus, nitrogen heteroatom could be efficiently introduced into the WPU/GO composite from WPU as a nitrogen-rich carbon. In addition, the specific surface area was increased by the boric acid treatment and washing process. The ferric catalyst treatment could prevent the formation of inert $\mathrm{B}-\mathrm{N}$ bonds. Thus, the synthesized B/ $\mathrm{N}$ co-doped carbon materials exhibited high specific capacitance $\left(330 \mathrm{~F} \mathrm{~g}^{-1}\right.$ at $0.5 \mathrm{~A} \mathrm{~g}^{-1}$ ), superior rate performance, and excellent cycling stability. Furthermore, the assembled symmetric supercapacitor displayed a good energy density $\left(7.9 \mathrm{~W} \mathrm{~h} \mathrm{~kg}^{-1}\right.$ at $505 \mathrm{~W} \mathrm{~kg}^{-1}$ ) and a good capacitance retention of about $89.9 \%$ after 5000 charge-discharge cycles in $6 \mathrm{M} \mathrm{KOH}$ electrolyte. Therefore, the as-prepared B/N co-doped carbon materials show a promising future in supercapacitor application.
\end{abstract}

\section{Introduction}

Supercapacitors have gained significant attention as an ideal energy storage apparatus for mobile devices, electric devices, and high-power equipment due to their fast charge-discharge rate, high power density, and long cycle life. ${ }^{1-3}$ In general, supercapacitors could be divided into two groups based on the mechanism of electrical energy storage: first, pseudocapacitance based on reversible redox reactions among electrode and electrolyte ions. Second, electrical double-layer capacitance through the electrochemical charge directional array on the electrode/electrolyte interface., ${ }^{4,5}$ At present, carbon-based materials have shown great significance in electrical doublelayer capacitors owing to their high specific surface area, good electrical conductivity and prominent physicochemical stability. ${ }^{6,7}$ Nevertheless, the specific capacitance and energy density of the capacitors fail to be improved further due to the limitations of carbon-based material structures. Therefore, researchers have sought to apply effective pseudocapacitance to carbon-based materials to improve the electrochemical performance.

In general, there are two approaches to introduce pseudocapacitance into carbon-based materials. First,

School of Chemical Engineering and Materials, Heilongjiang University, Harbin 150080, P. R. China.E-mail: jiangxiankai@hlju.edu.cn

$\dagger$ Electronic supplementary information (ESI) available. See DOI: 10.1039/c8ra09043b pseudocapacitive materials are introduced into carbon-based materials to synthesize composites, such as metal oxides and conducting polymers. Second, the introduction is achieved by doping heteroatoms $\left(\mathrm{N},{ }^{8} \mathrm{O},{ }^{9} \mathrm{~B},{ }^{10} \mathrm{~S},{ }^{11}\right.$ or $\left.\mathrm{P}^{12}\right)$, which can introduce redox reactions (pseudocapacitive behavior) and enhance the capacitive performance. ${ }^{\mathbf{1 3 - 1 8}}$ Doping heteroatoms into carbonbased materials could be considered as a better approach to increase the capacitive performance of supercapacitors without losing high power density and cycling stability as a result of the intrinsically-low conductivity and cycling stability of metal oxides and conducting polymers. In a general way, heteroatomdoped carbon (HDC) can be formed by two approaches: the first approach is post-treatment, where carbon-based materials are treated by reagents with heteroatoms, such as boric acid, ${ }^{\mathbf{1 9}}$ ammonia, ${ }^{20}$ and urea. ${ }^{21}$ However, the heteroatoms formed on the surface of carbon-based materials have an unsteady state. The second approach is an in situ method, where heteroatomdoped carbon is prepared by direct carbonization through the carbon precursors with heteroatoms, such as ionic liquids, biomass, and polymers. As the in situ method can dope the stable heteroatoms into the bulk of carbon in a homogeneous and easy way, this method is considered as a promising approach. Liu et al. ${ }^{22}$ synthesized N/O co-doped porous carbon from Perilla frutescens through direct carbonization with high specific capacitance $\left(270 \mathrm{~F} \mathrm{~g}^{-1}\right.$ at $\left.0.5 \mathrm{~A} \mathrm{~g}^{-1}\right)$.

Currently, the performance of the pseudocapacitance by carbon-based materials has been efficiently improved by doping various heteroatoms. The co-doping of different heteroatoms, 
for instance, electron-deficient boron and electron-rich nitrogen, into carbon-based materials could form a subtle electronic structure relating to the synergetic effect among the heteroatoms. Thus, co-doped carbon-based materials could exhibit better capacitive property. In fact, great progress has been made in the research of co-doping nitrogen and boron into carbon-based materials. Gao et $a l^{23}$ prepared boron and nitrogen co-doped activated carbon from precursors with boron and nitrogen after carbonization and a not-high specific capacitance was achieved $\left(268 \mathrm{~F} \mathrm{~g}^{-1}\right.$ at $\left.0.1 \mathrm{~A} \mathrm{~g}^{-1}\right)$. Dai et al. ${ }^{24}$ synthesized boron carbon nitride nanotubes from the precursor melamine as a single diborate via chemical vapor deposition (CVD) and a high specific capacitance was achieved $\left(321 \mathrm{~F} \mathrm{~g}^{-1}\right.$ at $\left.0.2 \mathrm{~A} \mathrm{~g}^{-1}\right)$. Fu et $a .^{25}$ synthesized boron and nitrogen co-doped porous carbon via carbonization with the ferric catalyst treatment from a precursor including nitrogen-containing chitosan and boric acid and an excellent specific capacitance was achieved (313 $\mathrm{F}^{\mathrm{g}}{ }^{-1}$ at $\left.1 \mathrm{~A} \mathrm{~g}^{-1}\right)$. Qin et al. ${ }^{26}$ used polyvinylpyrrolidone, melamine formaldehyde resin, urea, and boric acid to prepare a boron/nitrogen/oxygen co-doped carbon with high capacitive performance $\left(238 \mathrm{~F} \mathrm{~g}^{-1}\right.$ at $\left.0.5 \mathrm{~A} \mathrm{~g}^{-1}\right)$. The carbon-based materials with different heteroatoms require further improvement in their performance. Therefore, it is of great significance to prepare boron/nitrogen co-doped carbonbased materials with high electrochemical performance in an efficient and easy way.

Herein, B/N co-doped carbon materials were synthesized by an efficient and easy one-step carbonization method with ferric catalyst treatment from a precursor with boric acid treatment after the formation of composite between waterborne polyurethane (WPU) and graphene oxide (GO). The nitrogen content was improved with the introduction of numerous melamine in the synthetic process of WPU. In addition, WPU possessed a repetitive basic unit urethane bond (-NHCOO); thus, the nitrogen heteroatom could be efficiently introduced into the WPU/GO composite from WPU as a nitrogen-rich carbon. In addition, the specific surface area was increased by the boric acid treatment and washing process. The ferric catalyst treatment could prevent the formation of inert B-N bonds. Thus, the synthesized $\mathrm{B} / \mathrm{N}$ co-doped carbon materials exhibited high specific capacitance $\left(330 \mathrm{~F} \mathrm{~g}^{-1}\right.$ at $\left.0.5 \mathrm{~A} \mathrm{~g}^{-1}\right)$, superior rate performance, and excellent cycling stability. Furthermore, the assembled symmetric supercapacitor displayed a good energy density (7.9 $\mathrm{W} \mathrm{h} \mathrm{kg}^{-1}$ at $505 \mathrm{~W} \mathrm{~kg}^{-1}$ ) and a good capacitance retention of about $89.9 \%$ after 5000 charge-discharge cycles in $6 \mathrm{M} \mathrm{KOH}$ electrolyte. Therefore, the prepared $\mathrm{B} / \mathrm{N}$ co-doped carbon materials show a promising future in supercapacitor application.

\section{Experimental}

\subsection{Preparation of waterborne polyurethane}

All of the chemical reagents used in the experiments were of analytical reagent grade. First, $6.3 \mathrm{~g}$ of toluene-2,4diisocyanate and $6.3 \mathrm{~g}$ of acetone were mixed uniformly into a three-necked round-bottom flask, followed by stirring at $80{ }^{\circ} \mathrm{C}$ with a stirring rate of $250 \mathrm{rpm}$. Then, $1.3 \mathrm{~g}$ of 2,2- bis(hydroxymethyl) propionic acid dissolved in NMP was added into the flask dropwise. Thereafter, $8.5 \mathrm{~g}$ of polycarbonate diol dispersed in acetone was added into the mixture dropwise. Subsequently, $0.6 \mathrm{~g}$ of trimethylolpropane and $0.6 \mathrm{~g}$ of melamine were added separately into the reactants dropwise to react for $1 \mathrm{~h}$. The prepolymer was then cooled to ambient temperature and $0.95 \mathrm{~g}$ of triethylamine was introduced into the prepolymer to react for $20 \mathrm{~min}$. Subsequently, an appropriate amount of deionized water was added and waterborne polyurethane aqueous dispersion was synthesized.

\subsection{Preparation of $\mathrm{B} / \mathrm{N}$ co-doped carbon}

GO was synthesized from natural graphite according to the modified Hummer's method ${ }^{27}$ and was diluted to a $5 \mathrm{mg} \mathrm{mL}^{-1}$ suspension with deionized water for the following experiments. Subsequently, waterborne polyurethane aqueous dispersion and GO suspension were mixed with a solid content ratio of $30: 1$ at ambient temperature to form a homogeneous solution. Then, saturated boric acid and $1 \mathrm{M}$ ferric chloride solution (molar ratio $=1: 1$ ) were slowly added into the WPU/ GO solution in sequence and ultrasound dispersed at ambient temperature for $1 \mathrm{~h}$ to prepare the precursor solution. Next, the precursor was dried at $60{ }^{\circ} \mathrm{C}$ for $24 \mathrm{~h}$. Thereafter, the precursor was carbonized at $800{ }^{\circ} \mathrm{C}$ for $2 \mathrm{~h}$ at a heating rate of $5{ }^{\circ} \mathrm{C} \min ^{-1}$ in nitrogen atmosphere. Furthermore, the product was washed with $6 \mathrm{M} \mathrm{HCl}$ at ambient temperature for $6 \mathrm{~h}$ and boiled in deionized water at $80{ }^{\circ} \mathrm{C}$ for $6 \mathrm{~h}$ to remove the ferric catalyst and residual boron oxides. The final product was named WPU-GO-Fe-B. For comparison, WPU/GO solution containing saturated boric acid, WPU/GO solution containing $1 \mathrm{M}$ ferric chloride solution, and pure WPU/GO solution were disposed by the same process as described above, and they were named WPU-GO-B, WPU-GO-Fe, and WPU-GO, respectively. The preparation process of WPU-GO-Fe-B is shown in Fig. 1.

\subsection{Characterization}

The morphology of the samples was observed using an emission scanning electron microscopy (SEM, S-4800, Hitachi, Japan) and an transmission electronic microscopy (TEM, JEM-2100, JEOL Ltd, Japan). The crystal structure of the samples was analyzed by X-ray diffraction (XRD, D8 Advance, Bruker, Germany). Raman spectra were examined using a Raman spectrometer (HR800, Jobin Yvon, French) at $457.9 \mathrm{~nm}$. Fourier transform infrared spectra (FT-IR) were collected on a spectrometer (FT-IR, Equinox 55, Bruker, Germany). The surface elemental compositions of the samples were determined using X-ray photoelectron spectroscopy (XPS, ESCALAB 250, Thermo Fisher Scientific, UK). Nitrogen adsorption-desorption measurements were performed to characterize the porous structure of the samples using a physisorption instrument (ASAP 2020 HD88, Micromeritics, USA) at $77 \mathrm{~K}$. The conventional Brunauer-Emmett-Teller (BET) method was used to derive the specific surface area. The pore size distributions were determined using the Barrett-Joyner-Halenda (BJH) method. 


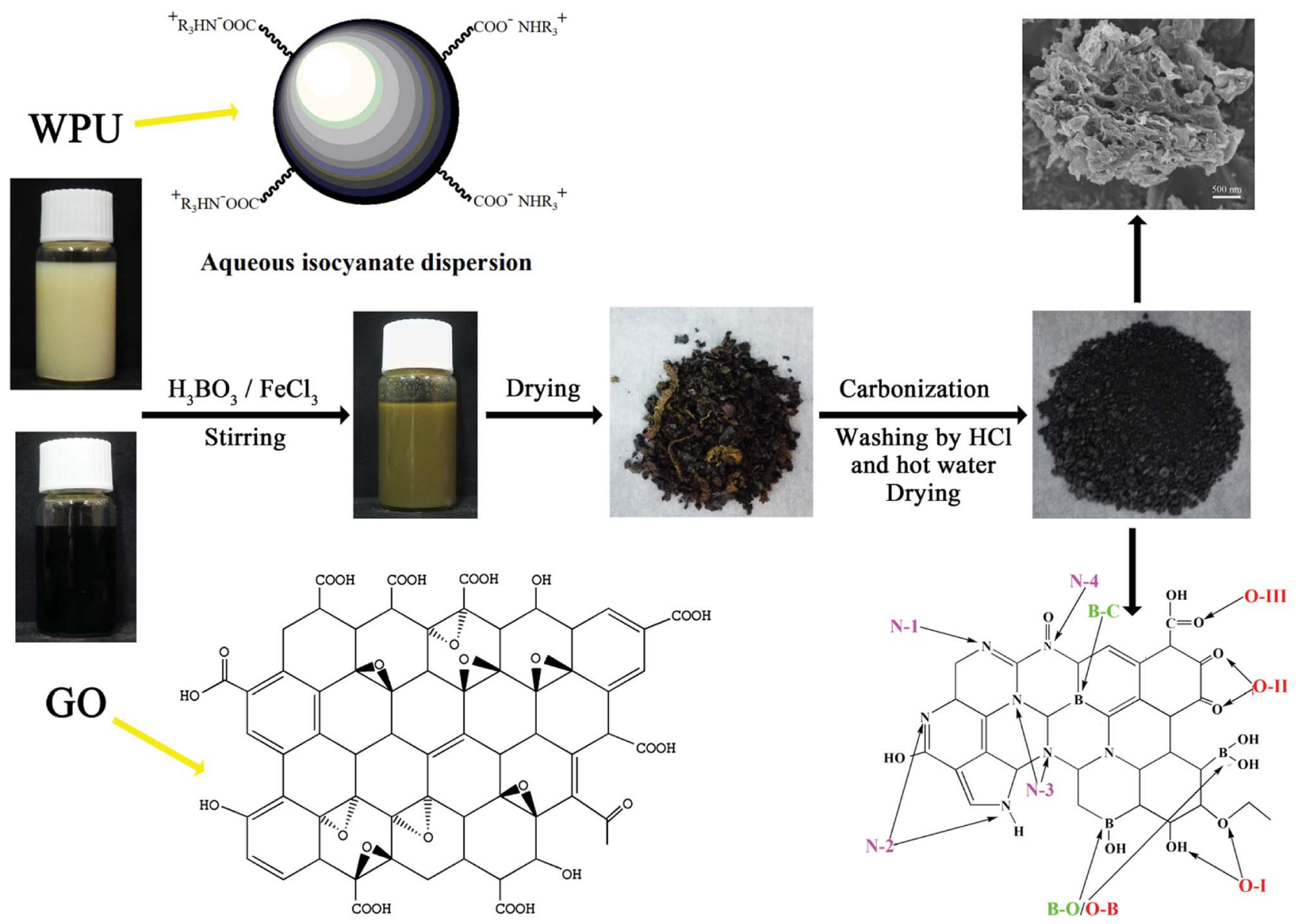

Fig. 1 Preparation process of WPU-GO-Fe-B.

\subsection{Electrochemical measurements}

For the three-electrode system, the electrochemical measurements of the samples were performed at ambient temperature in $6 \mathrm{M} \mathrm{KOH}$ aqueous electrolyte by an electrochemical workstation (CHI660E, Shanghai Chenhua, China). This system included a platinum electrode, a $\mathrm{Hg} / \mathrm{HgO}$ electrode, and a measured electrode as the counter electrode, reference electrode, and working electrode, respectively. The working electrode was prepared by coating the slurry, incorporating the active material and polytetrafluoroethylene binder with a mass ratio of $95: 5$ on a Ni-foam $(1 \mathrm{~cm} \times 1 \mathrm{~cm})$. The working electrode was loaded with approximately $5 \mathrm{mg} \mathrm{cm}^{-2}$ of active material. The cyclic voltammetry $(\mathrm{CV})$ curves were recorded in the potential range of $-1.0 \mathrm{~V}$ to $0 \mathrm{~V}$ at different scan rates ranging from $1 \mathrm{mV} \mathrm{s}^{-1}$ and $200 \mathrm{mV} \mathrm{s}^{-1}$. The galvanostatic charge/discharge (GCD) tests were conducted at a potential of $-1.0 \mathrm{~V}$ to $0 \mathrm{~V}$ at varying current densities. At the frequency range of $100 \mathrm{kHz}$ to $10 \mathrm{mHz}$, electrochemical impedance spectroscopy (EIS) tests were conducted with an AC voltage of $10 \mathrm{mV}$ at an open-circuit potential. The specific capacitance of the samples was calculated from GCD curves according to the equation:

$$
C=(I \times \Delta t) /(m \times \Delta V)
$$

where $C\left(\mathrm{~F} \mathrm{~g}^{-1}\right)$ is the specific capacitance of electrode material, $I(\mathrm{~A})$ is the current in the charge/discharge process, $\Delta t(\mathrm{~s})$ is the time difference in the discharge process, $m(\mathrm{~g})$ is the mass of activated material, and $\Delta V(\mathrm{~V})$ is the potential difference excluding the IR drop in the discharge process.

The cycling stability of the electrode materials was assessed by 2500 cycles $\mathrm{CV}$ tests at a scanning rate of $10 \mathrm{mV} \mathrm{s}^{-1}$. Then, its specific capacitance retention was analyzed.

For the two-electrode system, the assembled symmetric supercapacitor was composed of positive and negative electrodes made from active materials and the diaphragm from polypropylene. The working electrodes were prepared using the same process as described above. GCD tests were performed with a battery test instrument (CT2001A, Landiandianzi, China) with the potential range of $0 \mathrm{~V}$ to $1.0 \mathrm{~V}$ at varying current densities $\left(1 \mathrm{~A} \mathrm{~g}^{-1}, 2 \mathrm{~A} \mathrm{~g}^{-1}, 3 \mathrm{~A} \mathrm{~g}^{-1}, 5 \mathrm{~A} \mathrm{~g}^{-1}\right.$, and $\left.7 \mathrm{~A} \mathrm{~g}^{-1}\right)$. The specific capacitances, energy density and power density of the symmetric supercapacitor were calculated from the GCD curves by the following equations:

$$
\begin{gathered}
C_{\mathrm{p}}=(I \times \Delta t) /(m \times \Delta V) \\
C_{\mathrm{s}} \approx 4 C_{\mathrm{p}} \\
E_{\mathrm{p}}=\left(C_{\mathrm{p}} \times \Delta V^{2}\right) / 7.2
\end{gathered}
$$




$$
P=\left(3600 \times E_{\mathrm{p}}\right) / \Delta t
$$

where $C_{\mathrm{p}}\left(\mathrm{F} \mathrm{g}^{-1}\right), C_{\mathrm{s}}\left(\mathrm{F} \mathrm{g}^{-1}\right), E_{\mathrm{p}}\left(\mathrm{W} \mathrm{h} \mathrm{kg}^{-1}\right), P\left(\mathrm{~W} \mathrm{~kg}^{-1}\right)$ are the total specific capacitance of the assembled symmetric supercapacitor, the specific capacitance of a single electrode, the energy density of the symmetric supercapacitor, and the power density of the symmetric supercapacitor, respectively.

The cycling stability of symmetric supercapacitors was assessed by 5000 charge-discharge cycles with a current density of $5 \mathrm{Ag}^{-1}$. Then, its specific capacitance retention was analyzed.

\section{Results and discussion}

SEM images of the samples are shown in Fig. 2. The particles of waterborne polyurethane (Fig. 2a) in aqueous dispersion exhibited a spherical appearance with a diameter of approximately $20 \mu \mathrm{m}$. The irregular carbon particle from WPU (Fig. 2b) was formed because of the release of volatile substances (e.g. $\mathrm{NH}_{3}, \mathrm{CO}, \mathrm{CO}_{2}, \mathrm{H}_{2} \mathrm{O}$ ) during the carbonization process. Some carbon particles were observed in WPU-GO (Fig. 2c) and WPUGO-Fe (Fig. 2d) after the carbonization of waterborne polyurethane on the graphene oxide lamella, while WPU-GO-Fe showed a defective structure due to the removal of ferric catalyst in the washing process. WPU-GO-B (Fig. 2e) showed a similar structure; nevertheless, the presence of pore structure could be clearly observed compared with the WPU-GO because of the removal of boron oxides in the washing process. WPUGO-Fe-B (Fig. 2f) exhibited carbon particles on the graphene oxide lamella, and the carbon particle exhibited a more defective and disordered pore structure at high magnification. This structure could provide an interface for charge storage to improve the electrochemical performance of the electrical double-layer capacitance (EDLC). The TEM was further used to analyze the microscopic structure of WPU-GO-Fe-B. As shown in
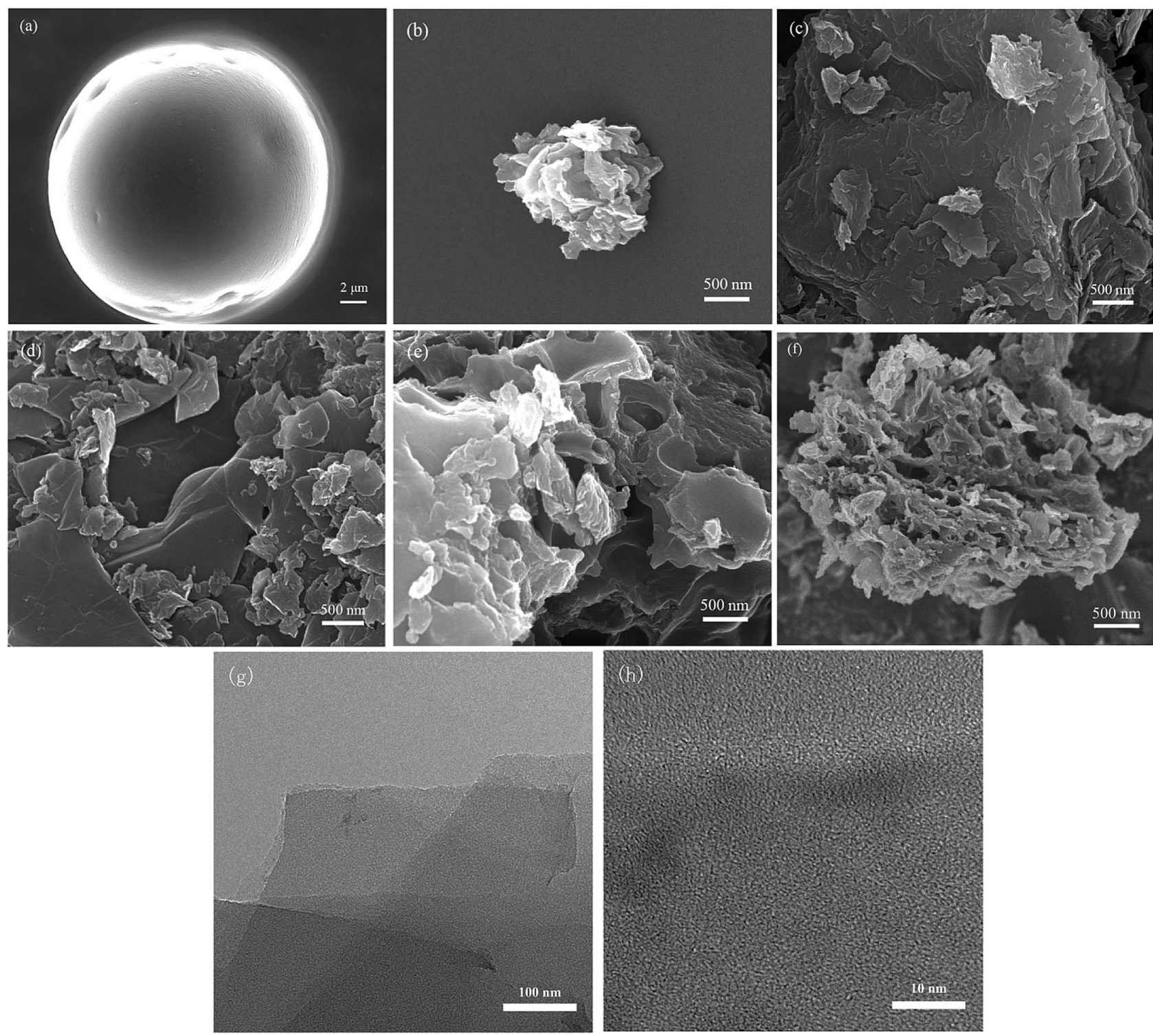

Fig. 2 SEM images of (a) particle of waterborne polyurethane in aqueous dispersion, (b) WPU after carbonization, (c) WPU-GO, (d) WPU-GO-Fe, (e) WPU-GO-B, (f) WPU-GO-Fe-B, (g) TEM images of WPU-GO-Fe-B, and (h) the high-resolution image of (g). 


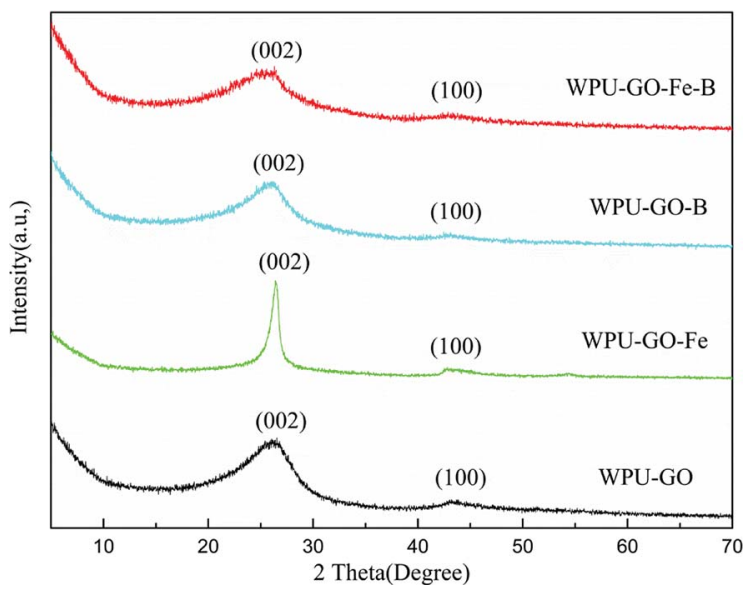

Fig. 3 XRD patterns of the WPU-GO, WPU-GO-Fe, WPU-GO-B, and WPU-GO-Fe-B samples.

Fig. 2g, WPU-GO-Fe-B displays a multilayer graphitic nanosheets structure, indicating that the WPU/GO composite formed a layered architecture after carbonization, which could correspond with the above-mentioned SEM test of WPU-GO-Fe-B. In addition, the high-resolution image (Fig. $2 \mathrm{~h}$ ) exhibits a disordered, interpenetrating, worm-like nanopores distribution on the graphitic nanosheets. The porous structure provides a large number for storage to electrolyte ion, which could improve the capacitive performance.

To visualize the change of the graphitization degree with different electrode materials, the XRD texts were analyzed, as shown in Fig. 3. Two diffraction peaks located at around $26^{\circ}$ and $43^{\circ}$ for all samples demonstrated the graphitic phase of the amorphous structure, which can be attributed to the (002) diffraction peak and (100) diffraction peak, respectively. Compared with WPU-GO, the (002) diffraction of WPU-GO-Fe was sharper, indicating that it could greatly improve the graphitization degree by adding the ferric catalyst. The (002) diffraction peak of WPU-GO-Fe-B was compared with that of WPU-GO-Fe, and the graphitization degree reduced due to the introduction of boric acid. According to the Bragg equation, WPU-GO-Fe-B, WPU-GO-B, WPU-GO-Fe, and WPU-GO showed (002) diffraction peaks at $2 \theta=25.6^{\circ}, 25.9^{\circ}, 26.4^{\circ}$, and $26.2^{\circ}$, respectively, which corresponded to the graphitic interlayer spacing $\left(d_{002}\right)$ of $3.48 \AA$, $3.43 \AA, 3.37 \AA$ and $3.40 \AA$, respectively. By comparison, the diffraction peaks shifted leftward with larger graphitic interlayer spacing $\left(d_{002}\right)$. The introduction of heteroatoms B into the hexagonal crystalline structure might result in the change in the graphitic interlayer spacing..$^{28}$

Raman spectra were used to further confirm the graphitic structure, and the results are shown in Fig. 4. There are two distinct peaks around $1380 \mathrm{~cm}^{-1}$ and $1590 \mathrm{~cm}^{-1}$ corresponding to the $\mathrm{D}$ band and $\mathrm{G}$ band, respectively. Generally, the $\mathrm{D}$ band can be attributed to the defect and disorder in carbon structure, while the $\mathrm{G}$ band indicates the ordered graphitic crystallites of carbon. ${ }^{29}$ The ratio of the $\mathrm{D}$ band and $\mathrm{G}$ band $\left(I_{\mathrm{D}} / I_{\mathrm{G}}\right)$ correlates to the graphitization extent of carbon. ${ }^{30}$ Herein, the $I_{\mathrm{D}} / I_{\mathrm{G}}$ ratios of WPU-GO-Fe-B, WPU-GO-B, WPU-GO-Fe, and WPU-GO were $0.72,0.78,0.26$, and 0.89 , respectively. The $I_{\mathrm{D}} / I_{\mathrm{G}}$ ratio of WPU-

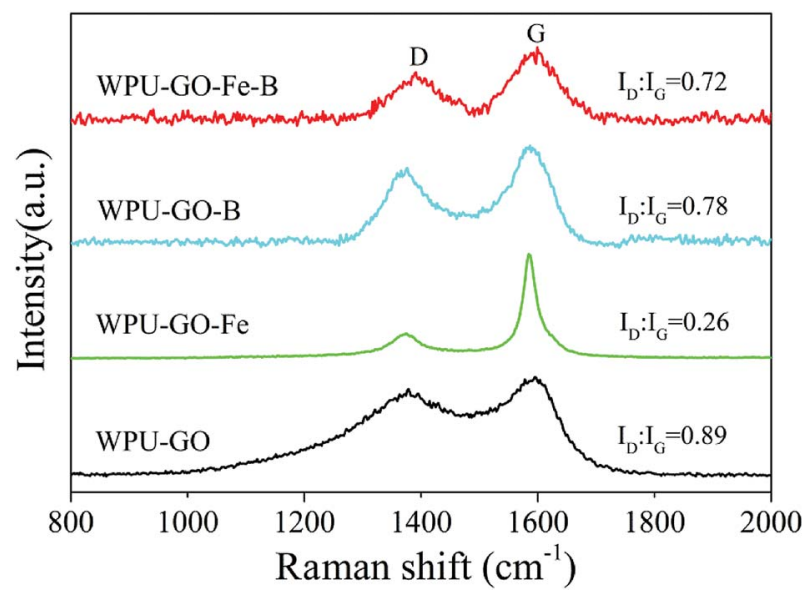

Fig. 4 Raman spectra of the WPU-GO, WPU-GO-Fe, WPU-GO-B, and WPU-GO-Fe-B samples.

GO-Fe was far below than that of WPU-GO, indicating that the graphitization degree of the carbon materials was significantly improved with the introduction of the ferric catalyst. Due to the structural defects by boric acid treatment, an increase in the $I_{\mathrm{D}} /$ $I_{\mathrm{G}}$ ratios of WPU-GO-Fe-B and WPU-GO-Fe was observed. WPUGO-Fe-B with a relatively small $I_{\mathrm{D}} / I_{\mathrm{G}}$ ratio showed better electronic conductivity, ${ }^{31}$ which could be demonstrated by EIS tests.

The functional groups of the samples were observed by FTIR, and the results are shown in Fig. 5. The FT-IR spectra of WPU-GO and WPU-GO-Fe only showed three peaks at around $1070 \mathrm{~cm}^{-1}, 1390 \mathrm{~cm}^{-1}$, and $1635 \mathrm{~cm}^{-1}$, corresponding to $\mathrm{C}-\mathrm{O}$ stretching vibration, $\mathrm{C}-\mathrm{N}$ stretching vibration and $\mathrm{C}=\mathrm{C}$ stretching vibration, respectively. ${ }^{28,32}$ In the FT-IR spectra of WPU-GO-B, the peaks at $1053 \mathrm{~cm}^{-1}, 1109 \mathrm{~cm}^{-1}, 1168 \mathrm{~cm}^{-1}$, $1270 \mathrm{~cm}^{-1}, 1385 \mathrm{~cm}^{-1}$, and $1632 \mathrm{~cm}^{-1}$ corresponded to the stretching vibrations of $\mathrm{C}-\mathrm{O}, \mathrm{B}-\mathrm{C}, \mathrm{B}-\mathrm{O}, \mathrm{B}-\mathrm{N}, \mathrm{C}-\mathrm{N}$, and $\mathrm{C}=\mathrm{C}$, respectively. ${ }^{28,32-34}$ It confirmed the $\mathrm{B} / \mathrm{N}$ coping in the carbon material. In comparison, in FT-IR spectra of WPU-GO-Fe-B, the peak corresponding to $\mathrm{B}-\mathrm{N}$ bond at $1270 \mathrm{~cm}^{-1}$ disappeared, and the peak at $1385 \mathrm{~cm}^{-1}$ corresponding to $\mathrm{C}-\mathrm{N}$ bond $\mathrm{d}^{32,34}$

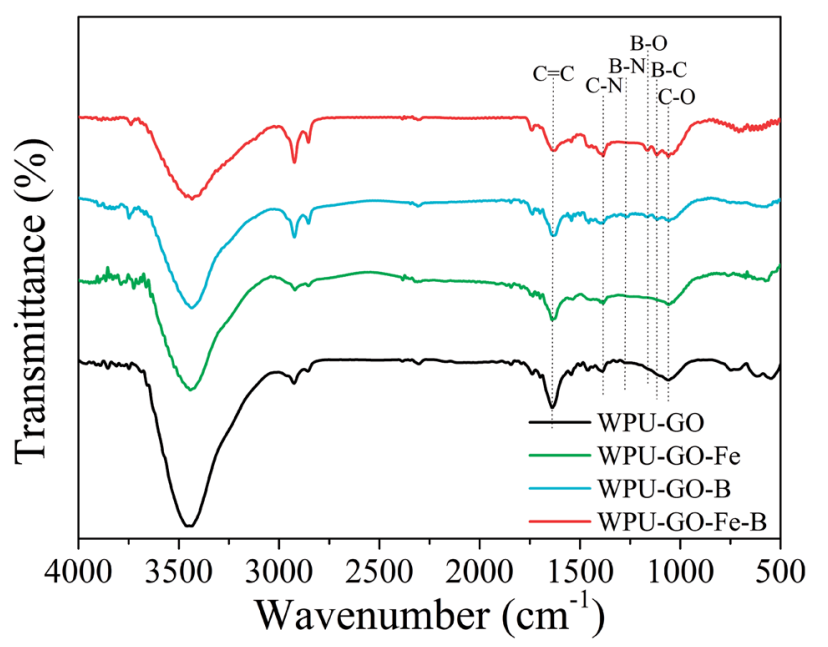

Fig. 5 FT-IR spectra of the WPU-GO, WPU-GO-Fe, WPU-GO-B, and WPU-GO-Fe-B samples. 
became noticeably enhanced on account of the introduction ferric catalyst, which prevented the direct bonding of boron and nitrogen atoms. ${ }^{25}$

XPS was used to investigate the chemical composition. The analysis spectrogram is exhibited in Fig. 6. The carbon structure model with boric acid and ferric catalyst treatment is shown in Fig. 6p. The surface elemental contents of the samples are shown in Table 1. As indicated by Fig. 6 and Table 1, both WPUGO and WPU-GO-Fe contained $\mathrm{C}, \mathrm{N}$ and $\mathrm{O}$ elements, while WPU-GO-B and WPU-GO-Fe-B contained B elements in addition to $\mathrm{C}, \mathrm{N}$, and $\mathrm{O}$ elements, implying that the $\mathrm{B}$ atoms were successfully introduced into the carbon structure. As exhibited by Fig. $6 \mathrm{a}-\mathrm{d}$, the $\mathrm{C} 1 \mathrm{~s}$ spectra were fitted to five peaks associating with $\mathrm{C}-\mathrm{B}(282.2 \mathrm{eV}), \mathrm{C}=\mathrm{C}(282.6 \mathrm{eV}), \mathrm{C}-\mathrm{N}(283.0 \mathrm{eV}), \mathrm{C}-\mathrm{O}(284.1$ $\mathrm{eV})$, and $\mathrm{C}=\mathrm{O}(287.7 \mathrm{eV}) .^{29,35}$ The N1 spectra (Fig. 6e-h) consisted of five peaks corresponding to the N-B bond $(395.8 \mathrm{eV})$, pyridinic nitrogen $(\mathrm{N}-1,396.6 \mathrm{eV})$, pyrrolic/pyridine nitrogen $(\mathrm{N}$ 2, $398.3 \mathrm{eV})$, quaternary nitrogen $(\mathrm{N}-3,400.8 \mathrm{eV})$, and $\mathrm{N}$-oxide atoms $(\mathrm{N}-4,402.6 \mathrm{eV}) .{ }^{36,37} \mathrm{O} 1 \mathrm{~s}$ peaks (Fig. 6i-l) exhibited $\mathrm{C}=\mathrm{O}$
(O-1, 528.7 eV), C-O (O-2, 529.9 eV), O-B (530.7 eV), and $\mathrm{O}=\mathrm{C}-\mathrm{O}$ $(\mathrm{O}-3,531.9 \mathrm{eV}){ }^{22,28,38}$ B1s (Fig. 6m-n) presented the peaks related to $\mathrm{B}-\mathrm{C}(190.7 \mathrm{eV}), \mathrm{B}-\mathrm{N}(191.1 \mathrm{eV})$, and $\mathrm{B}-\mathrm{O}(192.3 \mathrm{eV}){ }^{39,40}$ As expected, the existence of $\mathrm{B}$ atoms was verified by the $\mathrm{C}-\mathrm{B}$ in the C1s spectra, O-B bond in O1s spectra, and the peaks in B1s spectra. According to the XPS analysis results (Table 1), the heteroatoms contents of WPU-GO-B and WPU-GO-Fe-B were higher than that of NOC, demonstrating its superior pseudocapacitive behavior. The most important factors affecting the capacitive performance were $\mathrm{N}-1, \mathrm{~N}-2, \mathrm{C}-\mathrm{B}$, and $\mathrm{O}-1$ bonds. ${ }^{\mathbf{3 0 4}, \mathbf{4 2}}$ The relative contents of heteroatoms obtained from the analyses of the C1s N1s, B1s, and O1s peaks are shown in Table S1. $\dagger$ As can be found, WPU-GO-Fe-B exhibited high relative contents of N-1 (54.55 at\%), N-2 (33.83 at\%), C-B (57.36 at\%), and O-1 (19.69 at\%), suggesting that it could make a greater contribution in enhancing the pseudocapacitance performance. Moreover, the relative contents of inert $\mathrm{B}-\mathrm{N}$ disappeared in the spectra when compared with WPU-GO-B, demonstrating that ferric catalyst treatment could effectively prevent the formation
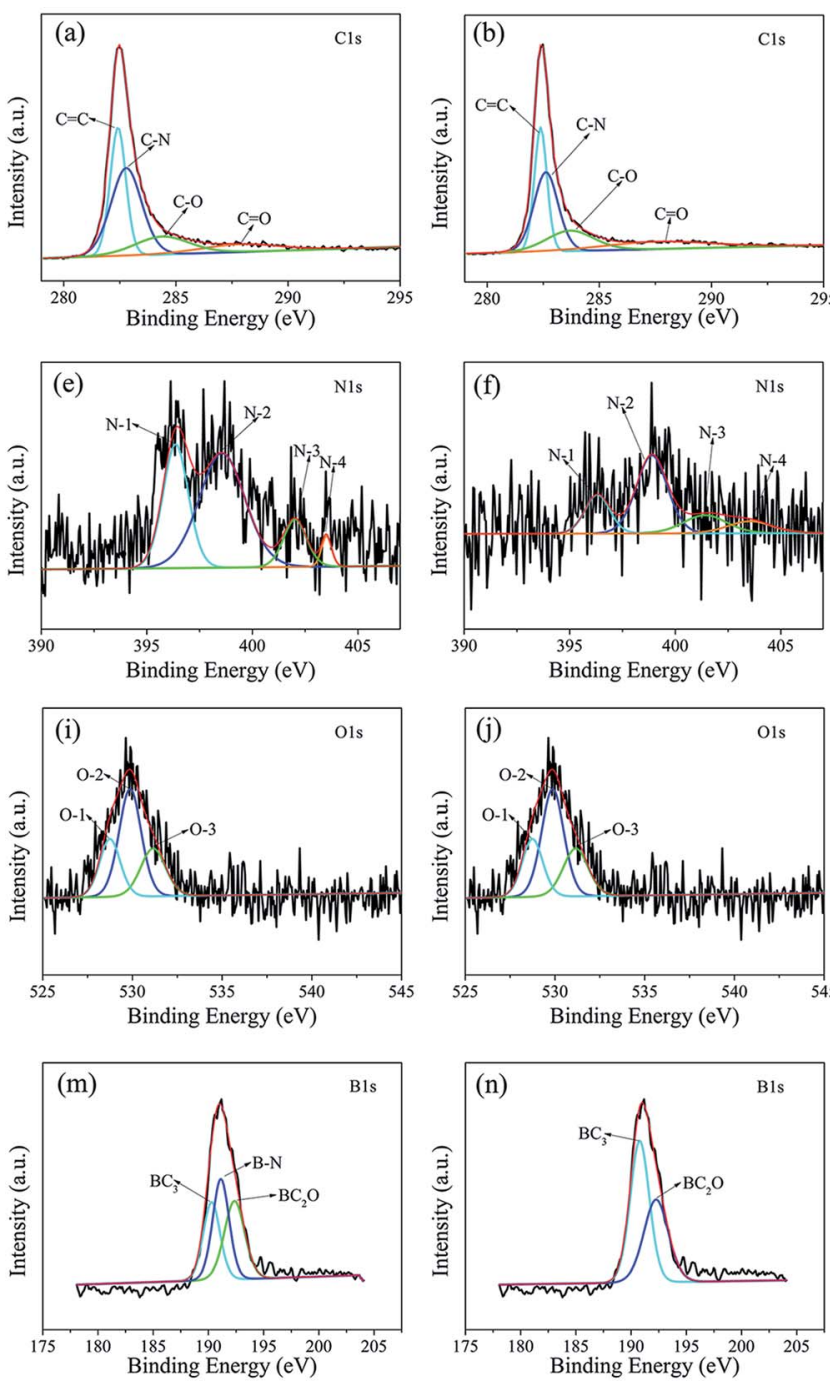
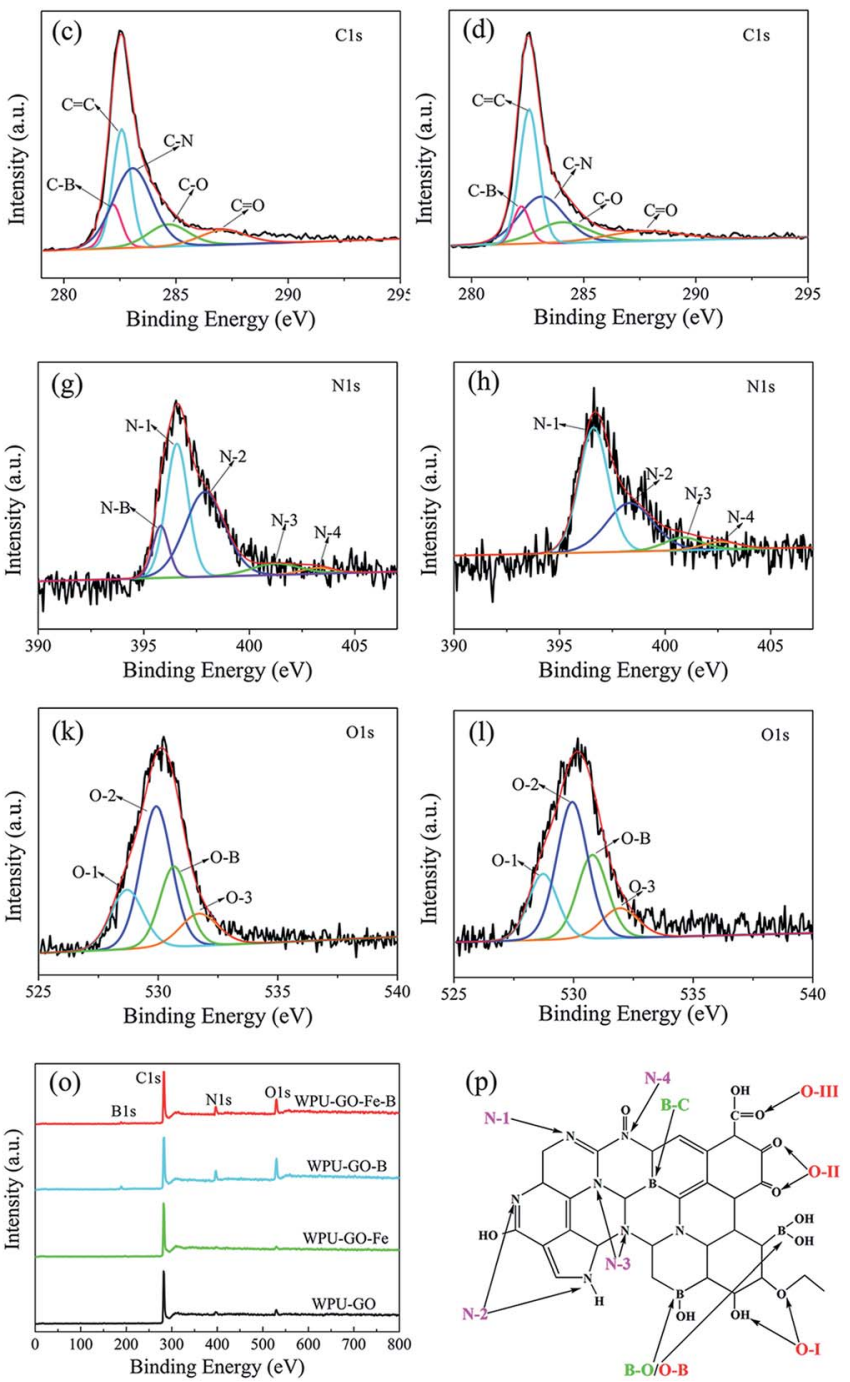

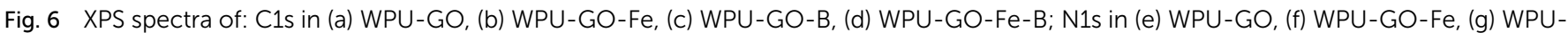

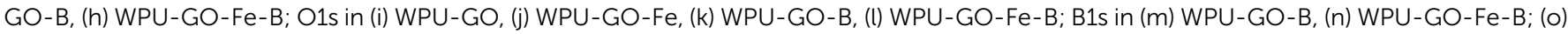
survey XPS spectrum of samples; (p) schematic of $N, B$, and $O$ atoms within carbon structure. 
Table 1 Morphological parameters and elemental contents of the WPU-GO, WPU-GO-Fe, WPU-GO-B, and WPU-GO-Fe-B samples

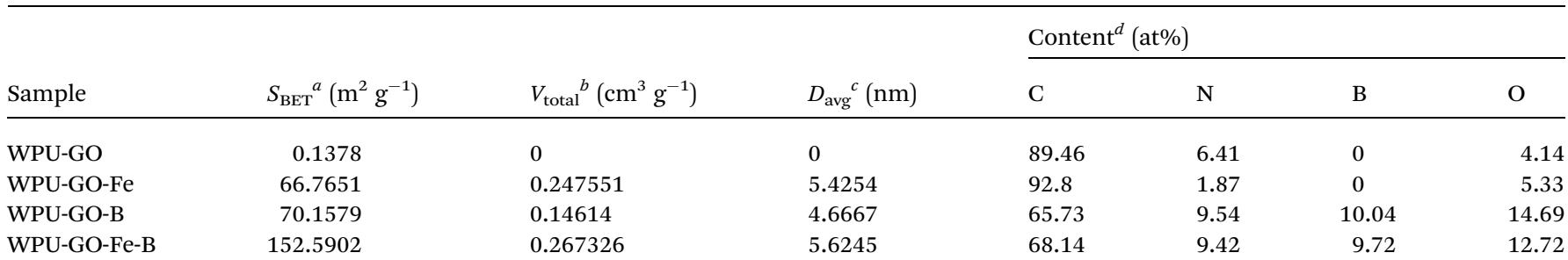

${ }^{a}$ Total specific surface area calculated by Brunauer-Emmett-Teller (BET) method. ${ }^{b}$ Total pore volume calculated at $P / P_{0}=0.99 .{ }^{c}$ Average pore diameter calculated from the equation of $4 V_{\text {total }} / S_{\mathrm{BET}}{ }^{d}$ Elemental contents of samples obtained from XPS analysis.

of inert B-N bonds and contribute to the constitution of active B-C bonds. As a result, WPU-GO-Fe-B exhibited greater pseudocapacitive performance than other samples.

Fig. 7 exhibits $\mathrm{N}_{2}$ adsorption/desorption isotherms and the pore size distributions of the samples. The isotherm of WPU-GO showed no rise, implying its low BET specific surface area. In contrast, the isotherms of WPU-GO-Fe, WPU-GO-B, and WPUGO-Fe-B presented characteristic type IV curves with the hysteresis loop. Almost no growth between the low $P / P_{0}$ relative pressures for the isotherm of samples indicated the few micropores. The hysteresis loop in the high $P / P_{0}$ area indicated the existence of mesopores. ${ }^{43}$ In addition, the pore size distribution (Fig. 7b) also indicated that the samples had some mesopores except for WPU-GO. As shown in Table 1, the WPUGO displayed extremely low BET specific surface area $\left(S_{\mathrm{BET}}\right)$ and total pore volume $\left(V_{\text {total }}\right)$ indicating its small amount of pore structure. Both the $S_{\mathrm{BET}}$ and $V_{\text {total }}$ of WPU-GO-Fe and WPU-GO-B increased noticeably. This might be due to the release of volatile substances during the carbonization process with a ferric catalyst or boric acid treatment. Furthermore, after the ferric catalyst or boron oxides were removed by the washing process, $S_{\mathrm{BET}}$ and $V_{\text {total }}$ also increased. Therefore, the porous characteristics of WPU-GO-Fe-B were further improved, leading to a further increase in $S_{\mathrm{BET}}$ and $V_{\text {total }}$ to $152.5902 \mathrm{~m}^{2} \mathrm{~g}^{-1}$ and $0.267326 \mathrm{~cm}^{3} \mathrm{~g}^{-1}$, respectively. Noteworthy to mention, these porous characteristics could play a crucial role in improving the ion transmission and double-layer capacitance, consequently improving the specific capacitance. , $^{\mathbf{2 , 4}, 45}$

To investigate the electrochemical performance, $6 \mathrm{M} \mathrm{KOH}$ electrolyte was used in testing the three-electrode system. Fig. 8a exhibits the CV curves of the electrode material at a scanning rate of $5 \mathrm{mV} \mathrm{s}^{-1}$. Each $\mathrm{CV}$ curve shows an approximately rectangular shape. In comparison, WPU-GO shows a small peak owing to the pseudocapacitance contributed by the $\mathrm{N}$ and $\mathrm{O}$ atoms. However, the WPU-GO-Fe curve exhibits an unobvious peak, which implies that its capacitance behavior was mainly determined by EDLC, resulting from the decrease in the heteroatom content (as shown in Table 1), and further reduced the pseudocapacitance. Besides, wide humps appeared on the CV curves of WPU-GO-B and WPU-GO-Fe-B, implying that their capacitance signified the combined action of EDLC and pseudocapacitance related to the various heteroatoms $\mathrm{N}, \mathrm{B}$, and $\mathrm{O}^{46}$ The $\mathrm{CV}$ curve of WPU-GO-Fe-B presents a larger area than that of WPU-GO-B, also indicating that introducing the ferric catalyst could prevent the formation of inert $\mathrm{B}-\mathrm{N}$ bonds. Fig. 8b exhibits the CV curves of WPU-GO-Fe-B at varying scanning rates. As can be seen, the curves of WPU-GO-Fe-B still maintain the quasi-rectangular shape with no obvious deformation when the scanning rate reached $50 \mathrm{mV} \mathrm{s}^{-1}$, indicative of its good rate performance. To demonstrate the capacitance contribution of the pseudocapacitance from heteroatoms, WPU-GO-Fe-B-900 was heat-treated from WPU-GO-Fe-B at
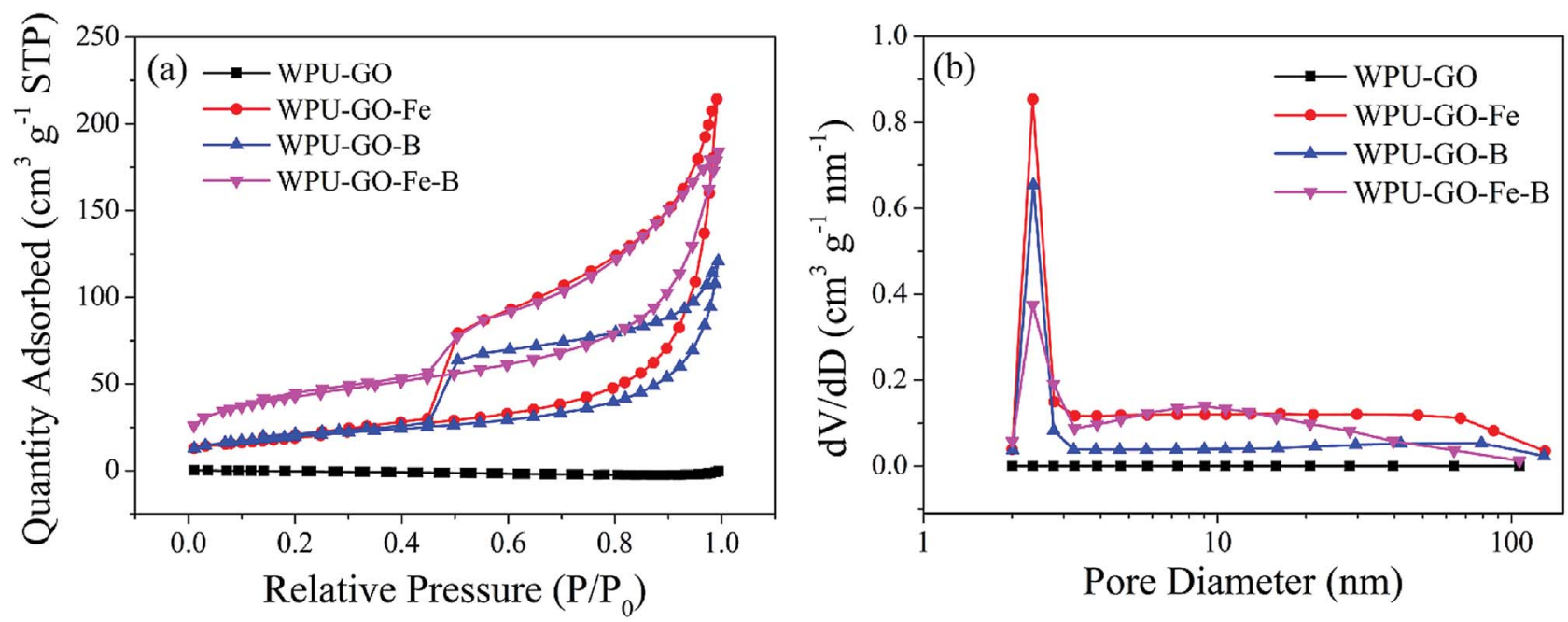

Fig. 7 (a) $\mathrm{N}_{2}$ absorption/desorption isotherms and (b) pore size distributions of the WPU-GO, WPU-GO-Fe, WPU-GO-B, and WPU-GO-Fe-B samples. 
(a)
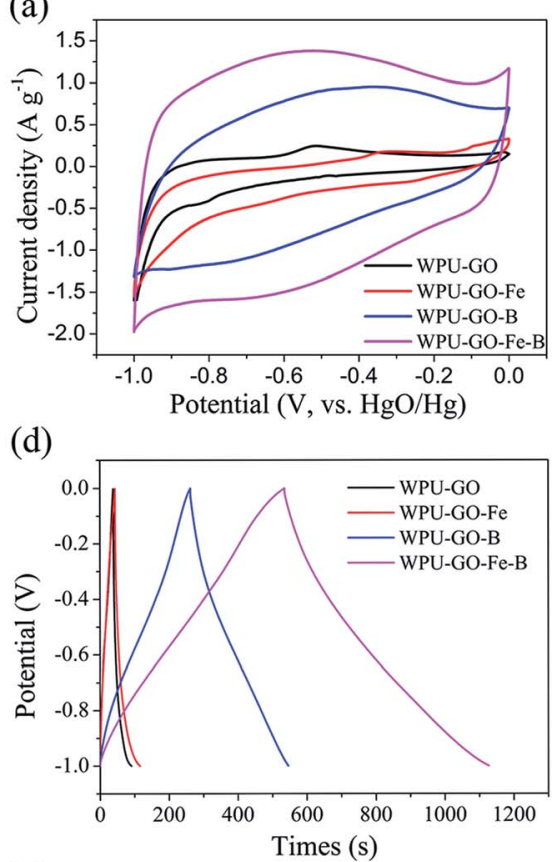

(g)

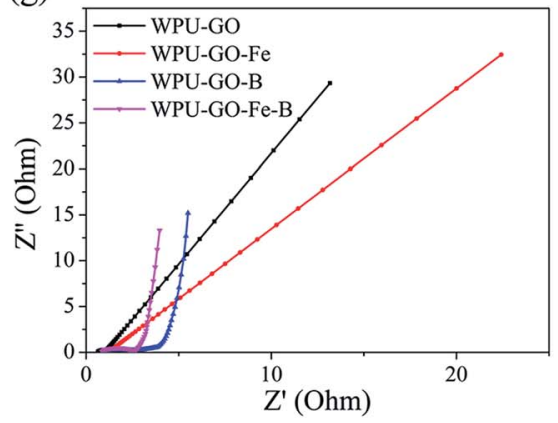

(b)

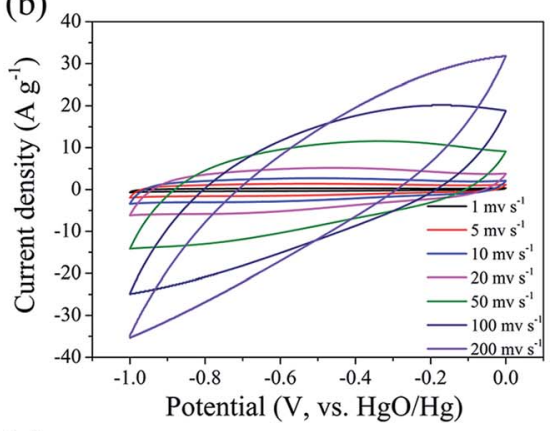

(e)

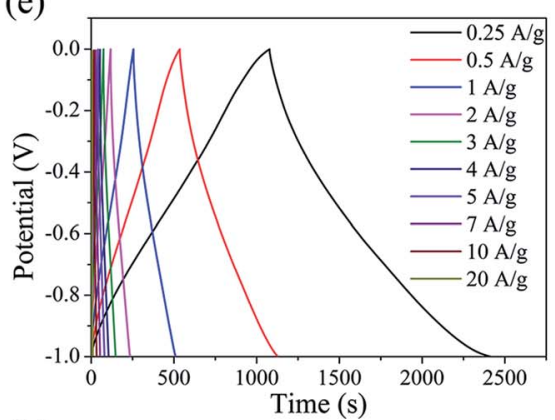

(h)

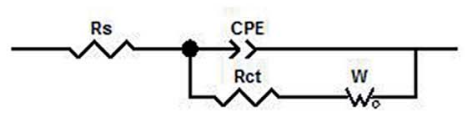

(c)

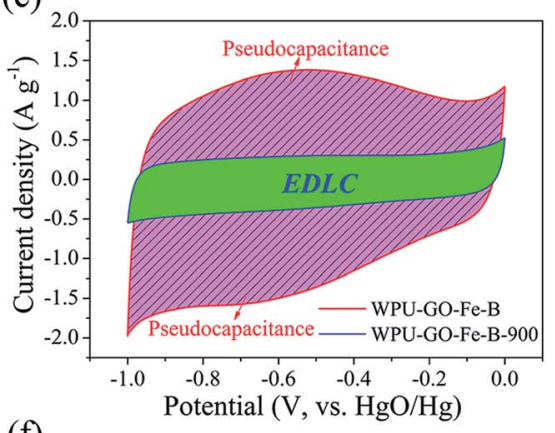

(f)

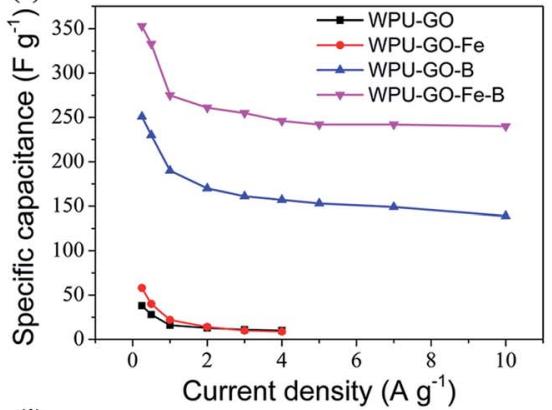

(i)

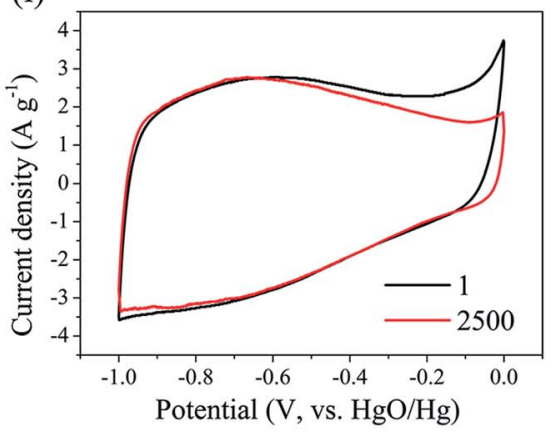

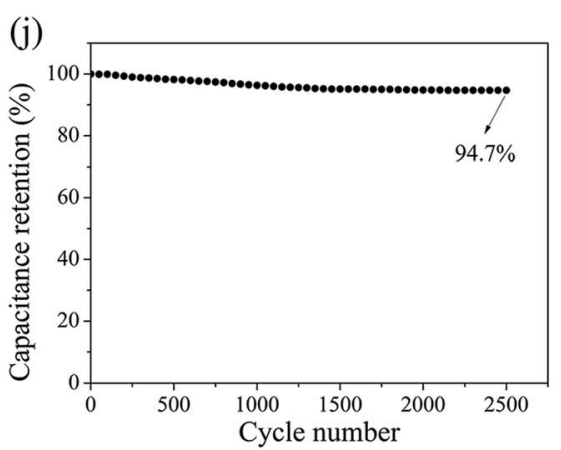

Fig. 8 Electrochemical performance in a three-electrode system: (a) CV curves of the samples at $5 \mathrm{mV} \mathrm{s}^{-1}$, (b) CV curves of WPU-GO-Fe-B at different scanning rates, (c) CV curves of WPU-GO-Fe-B and WPU-GO-Fe-B-900 at $5 \mathrm{mV} \mathrm{s}^{-1}$, (d) GCD curves of all samples at 0.5 A g ${ }^{-1}$, (e) GCD curves of WPU-GO-Fe-B at different current densities, (f) specific capacitance of the samples at different current densities, (g) Nyquist plots of all samples, (h) corresponding equivalent circuit model, (i) CV curves of WPU-GO-Fe-B at 1st and 2500 th cycles at $10 \mathrm{mV} \mathrm{s}^{-1}$, and (j) The capacitance retention of WPU-GO-Fe-B.

$900{ }^{\circ} \mathrm{C}$ for $2 \mathrm{~h}$ in a nitrogen atmosphere to eliminate the heteroatoms. The CV curve of WPU-GO-Fe-B-900 shows an orderly and limited rectangular shape without humps, as exhibited in Fig. 8c. This indicates that the main capacitance for WPU-GO-Fe-B was contributed by heteroatoms.

Fig. 8d shows the GCD curves of the samples at a current density of $0.5 \mathrm{~A} \mathrm{~g}^{-1}$. The quasi-symmetrical triangular shape resulted from the pseudocapacitive behavior from the heteroatoms. ${ }^{30}$ As exhibited in Fig. 8e, the charge/discharge time and the specific capacitance decreased gradually with the increase in current density because the materials were underutilized at the large current density. Fig. 8e exhibits the specific capacitance values of the samples at varying current densities calculated by eqn (1). The specific capacitance values of WPU-GO, WPU-GO-Fe, WPU-GO-B, and WPU-GO-Fe-B were $28 \mathrm{~F} \mathrm{~g}^{-1}, 40 \mathrm{~F} \mathrm{~g}^{-1}, 230 \mathrm{~F} \mathrm{~g}^{-1}$, and $330 \mathrm{~F} \mathrm{~g}^{-1}$ at $0.5 \mathrm{~A} \mathrm{~g}^{-1}$, 
Table 2 Comparison of specific capacitance for the obtained WPU-GO-Fe-B with those of previously reported samples

\begin{tabular}{|c|c|c|c|c|c|}
\hline Samples & Materials & Electrolyte & Current density & Capacitance & Ref. \\
\hline WPU-GO-Fe-B & In this work & $6 \mathrm{M} \mathrm{KOH}$ & $0.5 \mathrm{Ag} \mathrm{g}^{-1}$ & $330 \mathrm{~F} \mathrm{~g}^{-1}$ & In work \\
\hline N-PCFS & $\mathrm{N}$-doped porous carbon nanofibers & $6 \mathrm{M} \mathrm{KOH}$ & $1 \mathrm{Ag} \mathrm{g}^{-1}$ & $202 \mathrm{~F} \mathrm{~g}^{-1}$ & 47 \\
\hline $\mathrm{CNB}$ & $\mathrm{B} / \mathrm{N}$ co-doped porous carbon & $6 \mathrm{M} \mathrm{KOH}$ & $0.5 \mathrm{~A} \mathrm{~g}^{-1}$ & $247 \mathrm{~F} \mathrm{~g}^{-1}$ & 48 \\
\hline 1B-2CHI-WT & $\mathrm{B} / \mathrm{N}$ co-doped chitosan derived-porous carbons & $1 \mathrm{M} \mathrm{H}_{2} \mathrm{SO}_{4}$ & $0.1 \mathrm{~A} \mathrm{~g}^{-1}$ & $306 \mathrm{~F} \mathrm{~g}^{-1}$ & 49 \\
\hline $\mathrm{B} / \mathrm{N}-\mathrm{CS}$ & $\mathrm{B} / \mathrm{N}$ co-doped carbon nanosheets & $1 \mathrm{M} \mathrm{H}_{2} \mathrm{SO}_{4}$ & $0.1 \mathrm{~A} \mathrm{~g}^{-1}$ & $358 \mathrm{~F} \mathrm{~g}^{-1}$ & 50 \\
\hline BNC & $\mathrm{B} / \mathrm{N}$ co-doped graphene-like carbon & $6 \mathrm{M} \mathrm{KOH}$ & $0.25 \mathrm{~A} \mathrm{~g}^{-1}$ & $254 \mathrm{~F} \mathrm{~g}^{-1}$ & 53 \\
\hline $\mathrm{B} / \mathrm{N}-\mathrm{CNS}$ & $\mathrm{B} / \mathrm{N}$ co-doped carbon nanospheres & $1 \mathrm{M} \mathrm{H}_{2} \mathrm{SO}_{4}$ & $0.2 \mathrm{~A} \mathrm{~g}^{-1}$ & $423 \mathrm{~F} \mathrm{~g}^{-1}$ & 54 \\
\hline $\mathrm{PU} / \mathrm{CNT} / \mathrm{PAni}$ & Polyurethane/carbon-nanotube/polyaniline & $1 \mathrm{M} \mathrm{H}_{2} \mathrm{SO}_{4}$ & $0.9 \mathrm{~A} \mathrm{~g}^{-1}$ & $187 \mathrm{~F} \mathrm{~g}^{-1}$ & 55 \\
\hline Graphene/PU & Graphene/polyurethane composite film & $1 \mathrm{M} \mathrm{H}_{2} \mathrm{SO}_{4}$ & $0.5 \mathrm{~A} \mathrm{~g}^{-1}$ & $218 \mathrm{~F} \mathrm{~g}^{-1}$ & 56 \\
\hline
\end{tabular}

respectively, indicating that the introduction of boron atoms and ferric catalyst could significantly improve the capacitive property of the materials. WPU-GO-Fe-B exhibited the highest specific capacitance, especially since its specific capacitance could still maintain $68.0 \%$ retention after applying the current density of $10 \mathrm{~A} \mathrm{~g}^{-1}$ compared with $0.25 \mathrm{~A} \mathrm{~g}^{-1}$, indicating an excellent rate capability. As listed in Table 2, the performances of WPU-GO-Fe-B were better than those of many other heteroatom-doped carbon-based materials and polyurethanebased materials, showing that its good performance could be applied to supercapacitors.

The electrochemical behaviors of the samples were investigated by EIS measurements. Fig. $8 \mathrm{~g}$ exhibits the Nyquist plots of the samples. The Nyquist plots contain two parts, i.e.,
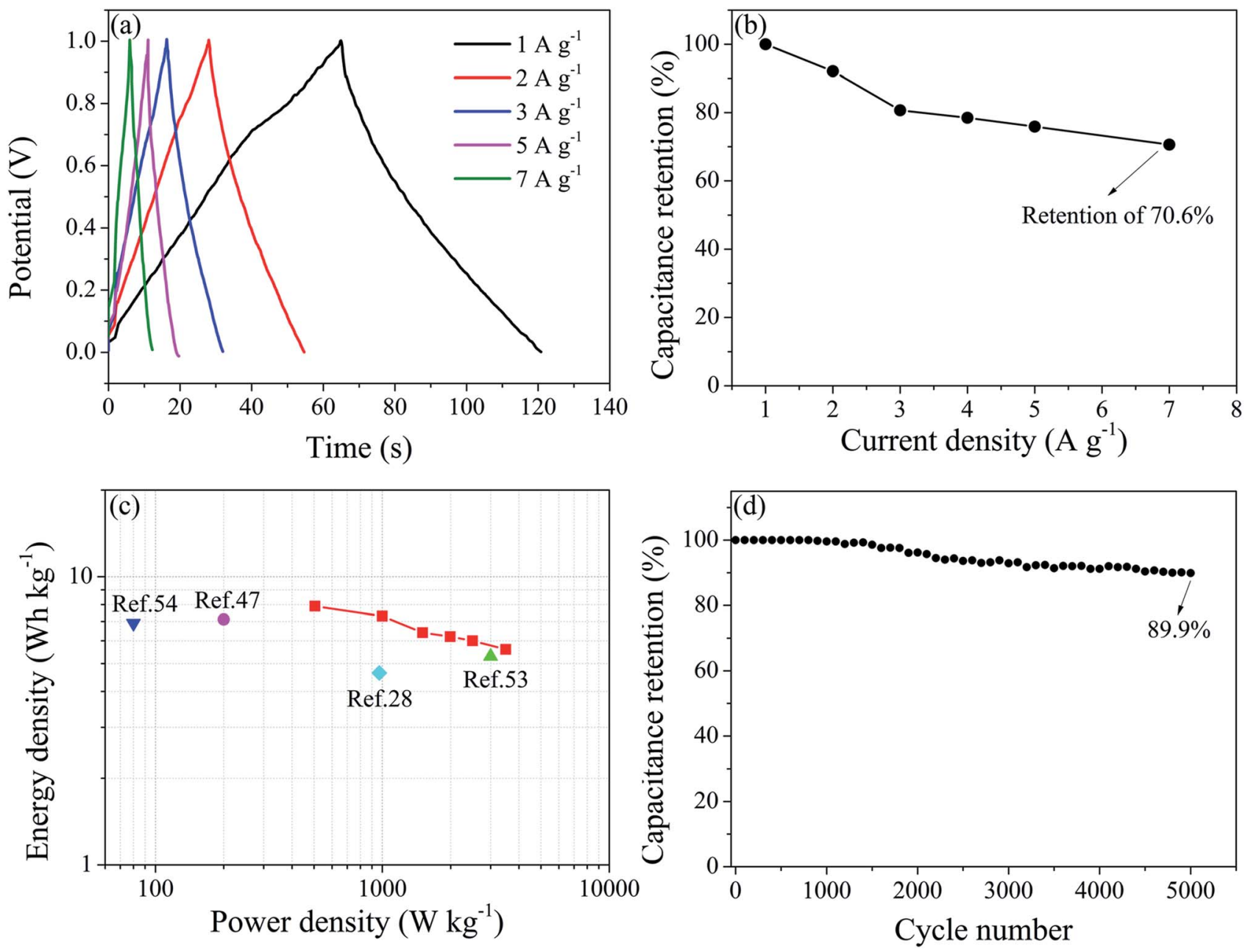

Fig. 9 Electrochemical performance of the WPU-GO-Fe-B//WPU-GO-Fe-B supercapacitor: (a) GCD curves at different current densities, (b) rate capability at different current densities, (c) Ragone plot of the WPU-GO-Fe-B//WPU-GO-Fe-B supercapacitor, and (d) cycling stability of the WPU-GO-Fe-B//WPU-GO-Fe-B supercapacitor at a current density of $5 \mathrm{~A} \mathrm{~g}^{-1}$. 
a hemicycle at a high frequency related to the charge transfer resistance of the electrons and ions as well as a straight line at low frequency linked to electrolyte ion transport in pore structures. Fig. $8 \mathrm{~h}$ displays an equivalent circuit model, including the electrolyte resistance $\left(R_{\mathrm{s}}\right)$, charge transfer resistance $\left(R_{\mathrm{ct}}\right)$, Warburg diffusion element $(W)$, and constant phase element (CPE). The fitted parameters of the samples are listed in Table S2. $\dagger$ As shown in Fig. 8g, at high frequency, WPU-GO-B and WPU-GO-Fe-B exhibited a large-radius semicircle compared with other samples, verifying the pseudocapacitive behavior from the heteroatoms. ${ }^{25}$ The $X$-intercept of curves denoted $R_{\mathrm{S}}$, and all samples showed minor $R_{\mathrm{S}}$ values $(<1.0 \Omega)$, indicating the low electrolyte resistance. Especially, WPU-GO-Fe-B exhibited the lowest $R_{\mathrm{S}}$ value, resulting from the increase in conductivity and electrochemical activity by the heteroatoms. ${ }^{26}$ At low frequency, WPU-GO-Fe-B showed a straight line with the highest slope of nearly $90^{\circ}$ to the $x$-axis, verifying the better capacitive characteristic of WPU-GO-Fe-B (perpendicular line of the ideal capacitor). In addition, the $R_{\mathrm{ct}}$ values of WPU-GO, WPUGO-Fe, WPU-GO-B, and WPU-GO-Fe-B were calculated as 0.81 $\Omega, 0.77 \Omega, 0.80 \Omega$, and $0.66 \Omega$, respectively. WPU-GO-Fe-B exhibited a minor $R_{\mathrm{ct}}$ value, which was beneficial for the charge transfer. ${ }^{45}$ Moreover, the WPU-GO-Fe-B with the smallest $W_{\mathrm{R}}$ value demonstrated the fast diffusion rate of electrolyte ions. In conclusion, WPU-GO-Fe-B exhibited good conductivity, fast charge transfer and high diffusion rate resulting in its excellent electrochemical performances.

Cycling stability plays a crucial part in supercapacitors. The cycling stability of WPU-GO-Fe-B was assessed by 2500 cycles of $\mathrm{CV}$ tests at a scanning rate of $10 \mathrm{mV} \mathrm{s}^{-1}$. The $\mathrm{CV}$ curve of WPUGO-Fe-B exhibits no obvious distortion until 2500 cycles as shown in Fig. 8i. Fig. 8j shows that WPU-GO-Fe-B still maintained $94.7 \%$ retention compared with the premier capacitance after 2500 cycles, indicating the good electrochemical stability and reversibility of WPU-GO-Fe-B.

To further investigate the electrochemical performances of WPU-GO-Fe-B, $6 \mathrm{M}$ KOH electrolyte was used in the symmetrical supercapacitor devices of a two-electrode system. Fig. 9a exhibits the GCD curves of the WPU-GO-Fe-B//WPU-GO-Fe-B supercapacitor at various current densities. Evidently, the WPU-GO-Fe-B//WPU-GO-Fe-B supercapacitor has a slightly distorted triangular shape, indicating the capacitive behavior from pseudocapacitive in the charge-discharge process. Calculated by eqn (2) and (3), the WPU-GO-Fe-B achieved good total specific capacitances $\left(57 \mathrm{~F} \mathrm{~g} \mathrm{~g}^{-1}\right.$ at $\left.1 \mathrm{~A} \mathrm{~g}^{-1}\right)$ and single electrode specific capacitances $\left(228 \mathrm{~F} \mathrm{~g}^{-1}\right.$ at $\left.1 \mathrm{~A} \mathrm{~g}^{-1}\right)$. Moreover, the capacitance retention still retained $70.6 \%$ when the current density increased from $1 \mathrm{~A} \mathrm{~g}^{-1}$ to $7 \mathrm{~A} \mathrm{~g}^{-1}$ (Fig. 9b), showing its good rate capability. According to the Ragone plots of the WPU-GO-Fe-B// WPU-GO-Fe-B supercapacitor (Fig. 9c), an energy density of $7.9 \mathrm{~W} \mathrm{~h} \mathrm{~kg}^{-1}$ was achieved at a power density of $505 \mathrm{~W} \mathrm{~kg}^{-1}$, and it still remained at $5.6 \mathrm{~W} \mathrm{~h} \mathrm{~kg}^{-1}$ at $3500 \mathrm{~W} \mathrm{~kg}^{-1}$. The performances were better than the previous research of boron-doped graphene (4.64 $\mathrm{W} \mathrm{h} \mathrm{kg}{ }^{-1}$ at $970 \mathrm{~W} \mathrm{~kg}^{-1}$ ), ${ }^{28}$ nitrogen-doped porous carbon (7.11 $\mathrm{W} \mathrm{h} \mathrm{kg}{ }^{-1}$ at $\left.200 \mathrm{~W} \mathrm{~kg}^{-1}\right),{ }^{47}$ boron/ nitrogen co-doped graphene-like carbon $\left(5.3 \mathrm{~W} \mathrm{~h} \mathrm{~kg}{ }^{-1}\right.$ at $\left.3000 \mathrm{~W} \mathrm{~kg}^{-1}\right),{ }^{53}$ and boron/nitrogen co-doped carbon nanospheres $\left(6.9 \mathrm{~W} \mathrm{~h} \mathrm{~kg}^{-1}\right.$ at $\left.80 \mathrm{~W} \mathrm{~kg}^{-1}\right),{ }^{54}$ etc. As shown in Fig. 9d, the WPU-GO-Fe-B//WPU-GO-Fe-B supercapacitor still maintained a capacitance retention of approximate $89.9 \%$ after 5000 charge-discharge cycles. Therefore, the assembled WPUGO-Fe-B has great potential to be applied to supercapacitors as the advanced heteroatoms in co-doped carbon materials.

\section{Conclusions}

In summary, this work presents an efficient and easy method to synthesize $\mathrm{B} / \mathrm{N}$ co-doped carbon materials with high, excellent capacitive performance. The heteroatoms $\mathrm{N}$ and $\mathrm{B}$ were introduced into the carbon materials by nitrogen-rich WPU and boric acid, respectively. Moreover, the graphitization degree was greatly improved, and the direct combination of the inert $\mathrm{B}-\mathrm{N}$ bond was effectively prevented by ferric catalyst treatment. As expected, WPU-GO-Fe-B displayed a high specific capacitance of $330 \mathrm{~F} \mathrm{~g}^{-1}$ at $0.5 \mathrm{~A} \mathrm{~g}^{-1}$ and good rate capability. The values of the performance indicators still remained at $94.7 \%$ compared with the premier capacitance after 2500 cycles. Furthermore, the asassembled WPU-GO-Fe-B//WPU-GO-Fe-B symmetric supercapacitor also exhibited a high energy density $\left(7.9 \mathrm{~W} \mathrm{~h} \mathrm{~kg}^{-1}\right.$ at $505 \mathrm{~W} \mathrm{~kg}^{-1}$ ) and showed a capacitance retention of approximately $89.9 \%$ after 5000 charge-discharge cycles. This work presents a feasible method to explore high-capability carbonbased materials potentially applicable to supercapacitors.

\section{Conflicts of interest}

There are no conflicts of interest to declare.

\section{Acknowledgements}

The authors are grateful for the support of the National Natural Science Foundation of China (Grant no. 21372067).

\section{Notes and references}

1 X. D. Yan, Y. H. Yu, S. K. Ryu, J. L. Lan, X. L. Jia and X. P. Yang, Electrochim. Acta, 2014, 136, 466.

2 C. L. Long, L. L. Jiang, X. L. Wu, Y. T. Jiang, D. R. Yang, C. K. Wang, T. Wei and Z. J. Fan, Carbon, 2015, 93, 412.

3 X. H. Xiong, D. Ding, D. C. Chen, G. Waller, Y. F. Bu, Z. X. Wang and M. L. Liu, Nano Energy, 2015, 11, 154.

4 J. Benson, I. Kovalenko, S. Boukhalfa, D. Lashmore, M. Sanghadasa and G. Yushin, Adv. Mater., 2013, 25, 6625.

5 J. Y. Wang, W. Dou, X. T. Zhang, W. H. Han, X. M. Mu, Y. Zhang, X. H. Zhao, Y. X. Chen, Z. W. Yang, Q. Su, E. Q. Xie, W. Lan and X. R. Wang, Electrochim. Acta, 2017, 224, 260.

6 B. C. Yang, C. X. Hao, F. S. Wen, B. C. Wang, C. P. Mu, J. Y. Xiang, L. Li, B. Xu, Z. S. Zhao, Z. Y. Liu and Y. J. Tian, ACS Appl. Mater. Interfaces, 2017, 9, 44478.

7 X. L. Wu, L. L. Jiang, C. L. Long and Z. J. Fan, Nano Energy, 2015, 13, 527.

8 Y. Y. Wang, J. Du, H. L. Zhang, L. Liu, Y. F. Yu, Y. Zhang, H. J. Lv and A. B. Chen, J. Electrochem. Soc., 2017, 164, A1918. 
9 W. Yang, W. Yang, L. Kong, S. Di and X. Qin, Front. Mater. Sci., 2018, 12(3), 283-291.

10 V. Thirumal, A. Pandurangan, R. Jayavel and R. Ilangovan, Synth. Met., 2016, 220, 524-532.

11 L. Sun, J. Liu, Z. Liu, T. Wang, H. Wang and Y. Li, RSC Adv., 2018, 8, 19964-19970.

12 J. Feng, W. Song, L. Sun and L. Xu, RSC Adv., 2016, 6, 110337110343.

13 L. Sun, L. Wang, C. G. Tian, T. X. Tan, Y. Xie, K. Y. Shi, M. T. Li and H. G. Fu, RSC Adv., 2012, 2, 4498-4506.

14 W. Ai, W. W. Zhou, Z. Z. Du, Y. P. Du, H. Zhang, X. T. Jia, L. H. Xie, M. D. Yi, T. Yu and W. Huang, J. Mater. Chem., 2012, 22, 23439-23446.

15 D. Carriazo, M. C. Gutiérrez, F. Picó, J. M. Rojo, J. L. G. Fierro, M. L. Ferrer and F. D. Monte, ChemSusChem, 2012, 5, 1405-1409.

16 L. F. Chen, X. D. Zhang, H. W. Liang, M. G. Kong, Q. F. Guan, P. Chen, Z. Y. Wu and S. H. Yu, ACS Nano, 2012, 6, 70927102.

17 L. Sun, C. G. Tian, Y. Fu, Y. Yang, J. Yin, L. Wang and H. G. Fu, J. Mater. Chem. A, 2013, 1, 6462-6470.

18 X. R. Wang, X. L. Li, L. Zhang, Y. Yoon, P. K. Weber, H. L. Wang, J. Guo and H. J. Dai, Science, 2009, 324, 768-771.

19 J. Gao, X. Y. Wang, Y. W. Zhang, J. Liu, Q. Lu and M. Liu, Electrochim. Acta, 2016, 207, 266.

20 D. Li, C. Yu, M. Wang, Y. Zhang and C. Pan, RSC Adv., 2014, 4, 55394-55399.

21 S. N. Faisal, E. Haque, N. Noorbehesht, W. Zhang, A. T. Harris, T. L. Church and A. I. Minett, RSC Adv., 2017, 7, 17950-17958.

22 B. Liu, Y. J. Liu, H. B. Chen, M. Yang and H. M. Li, J. Power Sources, 2017, 341, 309.

23 H. L. Guo and Q. M. Gao, J. Power Sources, 2009, 186, 551556.

24 E. Iyyamperumal, S. Y. Wang and L. M. Dai, ACS Nano, 2012, 6, 5259-5265.

25 L. Sun, Y. Fu, C. Tian, Y. Yang, L. Wang, J. Yin, J. Ma, R. Wang and H. Fu, ChemSusChem, 2014, 7, 1637-1646.

26 C. Wang, X. Zhang, J. Wang, Y. Ma, S. Lv, J. Xiang, M. Chu, T. Sun and C. Qin, J. Electrochem. Soc., 2018, 165(5), A1-A11.

27 W. Hummers and E. Offeman, J. Am. Chem. Soc., 1985, 80, 1339.

28 V. Thirumal, A. Pandurangan, R. Jayavel and R. Ilangovan, Synth. Met., 2016, 220, 524.

29 J. Ou, Y. Z. Zhang, L. Chen, Q. Zhao, Y. Meng, Y. Guo and D. Xiao, J. Mater. Chem. A, 2015, 3, 6534.

30 S. J. Song, F. W. Ma, G. Wu, D. Ma, W. D. Geng and J. F. Wan, J. Mater. Chem. A, 2015, 3, 18154.

31 Z. S. Li, B. L. Li, Z. S. Liu, D. H. Li, H. Q. Wang and Q. Y. Li, Electrochim. Acta, 2016, 190, 378.

32 W. Ai, W. W. Zhou, Z. Z. Du, Y. P. Du, H. Zhang, X. T. Jia, L. H. Xie, M. D. Yi, T. Yu and W. Huang, J. Mater. Chem., 2012, 22, 23439-23446.
33 J. Han, L. L. Zhang, S. Lee, J. Oh, K. Lee, J. R. Potts, J. Ji, X. Zhao, R. S. Ruoff and S. Park, ACS Nano, 2013, 7, 19-26.

34 S. Y. Wang, L. P. Zhang, Z. H. Xia, A. Roy, D. W. Chang, J. B. Baek and L. M. Dai, Angew. Chem., Int. Ed., 2012, 51, 4209.

35 S. B. Li, Z. F. Wang, H. M. Jiang, L. M. Zhang, J. Z. Ren, M. T. Zheng, L. C. Dong and L. Y. Sun, Chem. Commun., 2016, 52, 10988.

36 Y. Zheng, Y. Jiao, L. Ge, M. Jaroniec and S. Z. Qiao, Angew. Chem., 2013, 125, 3192.

37 Y. J. Kim, Y. Abe, T. Yanagiura, K. C. Park, M. Shimizu, T. Iwazaki, S. Nakagawa, M. Endo and M. S. Dresselhaus, Carbon, 2007, 45, 2116.

38 J. Zhou, H. L. Shen, Z. H. Li, S. Zhang, Y. Zhao, X. Bi, Y. S. Wang, H. Y. Cui and S. P. Zhuo, Electrochim. Acta, 2016, 209, 557.

39 Y. Zhao, L. J. Yang, S. Chen, X. Z. Wang, Y. W. Ma, Q. Wu, Y. F. Jiang, W. J. Qian and Z. Hu, J. Am. Chem. Soc., 2013, 135, 1201.

40 L. Wang, P. Yu, L. Zhao, C. G. Tian, D. D. Zhao, W. Zhou, J. Yin, R. H. Wang and H. G. Fu, Sci. Rep., 2014, 4, 5184.

41 M. Enterría, M. F. R. Pereira, J. I. Martins and J. L. Figueiredo, Carbon, 2015, 95, 72.

42 H. L. Shen, J. Zhou, Y. T. Zhao, S. Zhang, X. Bi, S. P. Zhuo and H. Y. Cui, RSC Adv., 2016, 6, 58764.

43 Z. L. Wang, X. B. Zhang, X. J. Liu, M. F. Lv, K. Y. Yang and J. Meng, Carbon, 2011, 49, 161-169.

44 H. W. Wang, C. Wang, Y. Xiong, C. D. Jin and Q. F. Sun, J. Electrochem. Soc., 2017, 164, A3832.

45 B. H. Kim, K. S. Yang and H. G. Woo, Mater. Lett., 2013, 93, 190.

46 H. L. Guo and Q. M. Gao, J. Power Sources, 2009, 186, 551.

47 L. F. Chen, X. D. Zhang, H. W. Liang, M. G. Kong, Q. F. Guan, P. Chen, Z. Y. Wu and S. H. Yu, ACS Nano, 2012, 8, 7092.

48 D. C. Guo, J. Mi, G. P. Hao, W. Dong, G. Xiong, W. C. Li and A. H. Lu, Energy Environ. Sci., 2013, 6, 652.

49 Z. Ling, G. Wang, M. Zhang, X. Fan, C. Yu, J. Yang, N. Xiao and J. Qiu, Nanoscale, 2015, 7, 5120-5125.

50 Z. Ling, Z. Wang, M. Zhang, C. Yu, G. Wang, Y. Dong, S. Liu, Y. Wang and J. Qiu, Adv. Funct. Mater., 2016, 26, 111-119.

51 Y. Chang, C. Yuan, C. Liu, J. Mao, Y. Li, H. Wu, Y. Wu, Y. Xu, B. Zeng and L. Dai, J. Power Sources, 2017, 365, 354-361.

52 Q. Lu, Y. Xu, S. Mu and W. Li, New Carbon Mater., 2017, 32(5), 442-450.

53 Z. Chen, L. Hou, Y. Cao, Y. Tang and Y. Li, Appl. Surf. Sci., 2018, 435, 937-944.

54 J. Hao, J. Wang, S. Qin, D. Liu, Y. Li and W. Lei, J. Mater. Chem. A, 2018, 6, 8053-8058.

55 A. Khosrozadeh, M. A. Darabi, Q. Wang and M. Xing, J. Mater. Chem. A, 2017, 5, 7933-7943.

56 Z. Tai, X. Yan and Q. Xue, J. Power Sources, 2012, 213, 350357. 